Article

\title{
Reduction of Furfural to Furfuryl Alcohol in Liquid Phase over a Biochar-Supported Platinum Catalyst
}

\author{
Ariadna Fuente-Hernández, Roland Lee, Nicolas Béland, Ingrid Zamboni \\ and Jean-Michel Lavoie * \\ Industrial Research Chair on Cellulosic Ethanol and Biocommodities (CRIEC-B), \\ Department of Chemical \& Biotechnological Engineering, Université de Sherbrooke, \\ Sherbrooke, QC J1K2R1, Canada; ariad22p@yahoo.com (A.F.-H.); roland.lee2@hotmail.com (R.L.); \\ nicolas.beland@gmail.com (N.B.); ingrid.rocio.zamboni.corredor@USherbrooke.ca (I.Z.) \\ * Correspondence: jean-michel.lavoie2@usherbrooke.ca; Tel.: +1-819-821-8000 (ext. 65505)
}

Academic Editor: Mejdi Jeguirim

Received: 7 December 2016; Accepted: 23 February 2017; Published: 28 February 2017

\begin{abstract}
In this work, the liquid phase hydrogenation of furfural has been studied using a biochar-supported platinum catalyst in a batch reactor. Reactions were performed between $170{ }^{\circ} \mathrm{C}$ and $320{ }^{\circ} \mathrm{C}$, using $3 \mathrm{wt} \%$ and $5 \mathrm{wt} \%$ of Pt supported on a maple-based biochar under hydrogen pressure varying from 500 psi to 1500 psi for reaction times between $1 \mathrm{~h}$ and $6 \mathrm{~h}$ in various solvents. Under all reactive conditions, furfural conversion was significant, whilst under specific conditions furfuryl alcohol (FA) was obtained in most cases as the main product showing a selectivity around $80 \%$. Other products as methylfuran (MF), furan, and trace of tetrahydrofuran (THF) were detected. Results showed that the most efficient reaction conditions involved a 3\% Pt load on biochar and operations for $2 \mathrm{~h}$ at $210{ }^{\circ} \mathrm{C}$ and $1500 \mathrm{psi}$ using toluene as solvent. When used repetitively, the catalyst showed deactivation although only a slight variation in selectivity toward FA at the optimal experimental conditions was observed.
\end{abstract}

Keywords: biochar; furfural; furfuryl alcohol (FA); hydrogenation; maple; platinum catalyst

\section{Introduction}

Production of second-generation biofuels as cellulosic ethanol should involve the valorization of every macromolecular fraction of the biomass in order to be economical [1]. Contrarily to the C6 carbohydrates, which are ideal candidates for classical fermentation, valorization of C5 sugars remains a challenge, either through biological or chemical pathways. Many biological alternatives have been investigated including fermentation to ethanol using, as an example, E. coli [2], Z. mobilis [3], and P. stipitis [4]. However, most of these approaches are limited by the kinetics of the fermentation, which usually involves longer fermentation periods as compared to their classical C6 counterparts.

As an alternative to the biological conversion of C5 sugars, another approach leading to their conversion could imply chemical processes. In a recent review, Fuente-Hernández et al. investigated the possible option of the conversion of xylose including reduction, oxidation, acid and base treatments [5]. Amongst the latter, acid treatments, leading to furfural have been thoroughly investigated and reported in literature [6,7]. Furfural with an annual global demand ranging between $20 \mathrm{kton} /$ year and $30 \mathrm{kton} /$ year can be used as chemical but could as well be used as a platform chemical for other compounds including but not limited to levulinic acid [8]. However, conversion of furfural to levulinic acid is not possible and must go through a reduction of the aldehyde function of furfural into an alcohol, thus producing furfuryl alcohol (FA).

Previous work from open literature reported that catalytic hydrogenation of furfural could be carried out either in the liquid [9] or vapor phase [10,11]. As for the industrial processes, they are 
generally conducted at high temperatures and pressures at which operations both in liquid and gas phase were reported. In terms of catalyst, the most popular for the reduction of furfural at industrial levels are $\mathrm{Ni}$ and $\mathrm{Cu} / \mathrm{Cr}$-based catalysts, although these catalysts exhibit a moderate activity towards FA [12,13]. At bench level, numerous reports have been made on the hydrogenation of furfural in liquid-phase using noble metal-based catalysts, such as palladium [14], platinum [9,13,15,16], iridium and ruthenium [17], rhodium [18], and zirconium oxide [19]. Reactions were performed either with or without a solvent (using different solvent types) sometimes even using a second metal (or a promoter) to improve the activity and/or the selectivity $[13,20,21]$. Amongst the non-noble metals that have been reported to selectively hydrogenate $\alpha, \beta$-unsaturated aldehydes, iron [22] and nickel [13] were the most commonly cited. The best example of the duality of two metals was reported when a combination of nickel and copper showed interesting characteristics of chemo-regio-, and, stereoselectivity for hydrogenation reactions $[13,20,21]$.

The choice of the support is also a key aspect that may lead to significant changes in catalytic activity. The most conventional supports are either acidic or basic oxides such as silica [22], alumina [14,23], and porous metal (Raney type) [24]. However, other types of supports (such as carbon) were also used for the production of reducing catalyst for chemoselective hydrogenations. Although the most common carbon support would certainly be activated carbon [25], biochar could as well be a cheap, stable, carbon-rich compound that could be considered to this purpose. The latter can be produced by "thermo" processes for biomass conversion such as torrefaction, pyrolysis, or gasification. It is made from renewable material and the already available inorganics that could be found in trace amounts in the biochar could influence the output of a catalytic reaction when used as support. Although activated carbon has been used as a catalytic support for hydrogenation reactions most probably as a mean to standardize catalyst synthesis, there is, to the best of our knowledge no report on the utilization of biochar as a support for hydrogenation reactions.

In this work, we report on the liquid phase hydrogenation of furfural to FA, which was used as a model compound of biomass-derived feedstock, by using a biochar-supported platinum catalyst. In addition, various reaction parameters such as metal loading in the catalyst, operating pressure of hydrogen, reaction time, solvent choice, and reaction temperature were studied to optimize furfural conversion, FA selectivity, and to determine kinetic parameters for catalysis reaction. Specific attention was given to the regeneration of the catalyst in order to link with further downstream industrial applications.

\section{Results and Discussion}

\subsection{Support Synthesis and Functionalization}

Biochar (BC) produced from torrefaction (slow pyrolysis) may contain bio-oils and traces of metal both from the pyrolysis process as well as from the original biomass. Bio-oils were removed using an Acid treatment (Section 3.1) prior to catalytic metal impregnation [26].

\subsection{Catalyst Characterization}

The scanning electron microscopy (SEM) morphology of both biochar support and platinum catalyst $\mathrm{Pt} / \mathrm{BC}$ revealed that the metal particles were not homogeneously distributed in the support, as shown in Figure 1. This lack of homogeneity in the distribution of the Pt can be seen from its tendency to agglomerate (Figure $1 \mathrm{~b}$ ).

Energy-dispersive X-ray (EDX) spectroscopy microanalysis was performed in order to determine the elemental analysis of the surface samples. The biochar (support without impregnation) spectrum revealed the presence of $\mathrm{C}, \mathrm{O}, \mathrm{Al}, \mathrm{K}$ and $\mathrm{Ca}$ elements in trace amounts (Figure 1a). As for comparison, the metal loading deposited during the impregnation is shown in Figure 1b. The EDX results indicate the presence of platinum as well as sulfur coming from the biochar treatment with the sulfuric acid solution. Copper most likely coming from the original biomass is not present in Figure 1a, which can 
be explained by the low amounts contained in the support, the heterogeneity of the sample, and by the size of the scan frame. The chlorine present in the impregnated catalyst probably comes from the platinum precursor.
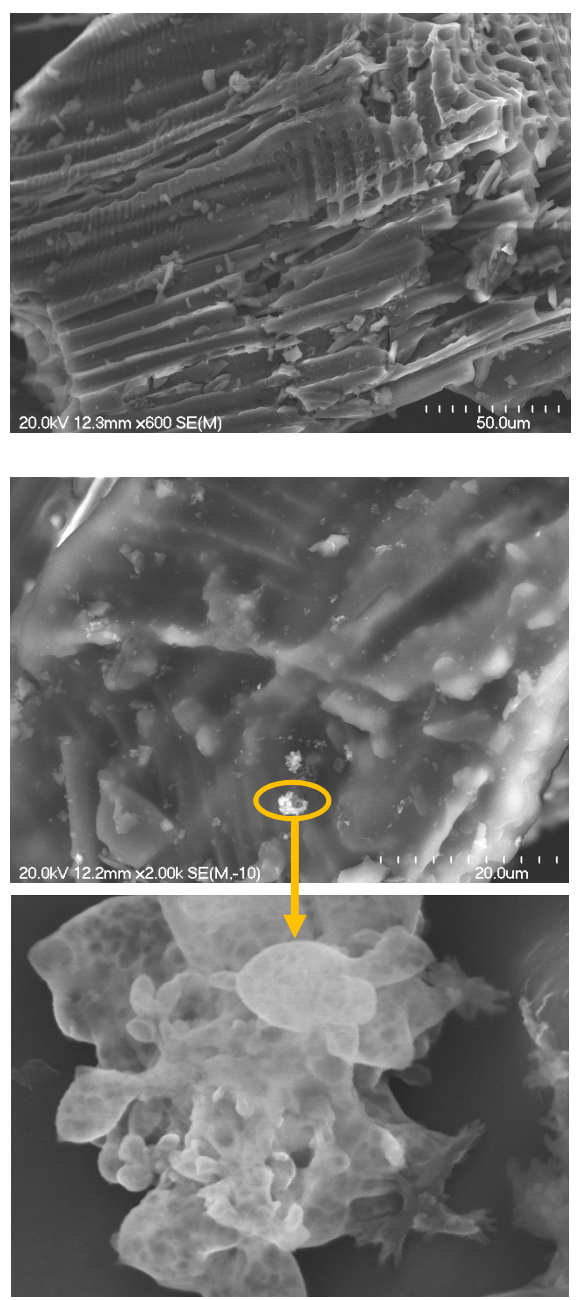

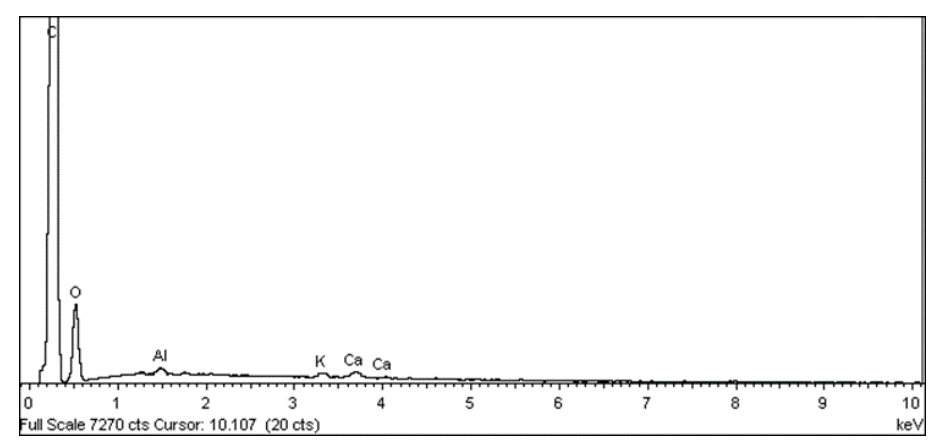

(a)

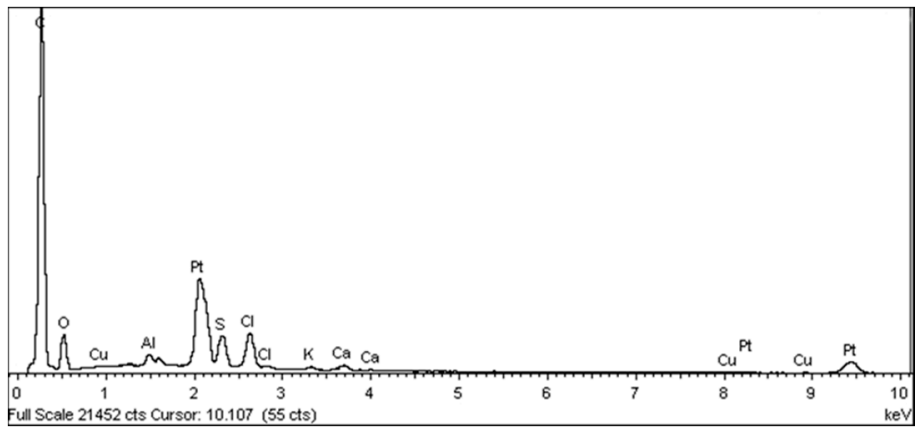

(b)

Figure 1. Scanning electron microscopy (SEM) images and energy-dispersive X-ray (EDX) spectra of biochar for the: (a) unimpregnated support; and (b) impregnated with $\mathrm{Pt} 3 \mathrm{wt} \%$ prior to the reaction.

\subsection{Catalyst Test with $P t / B C$}

The pathway leading to the products observed during furfural hydrogenation can be simplified as suggested in Figure 2. The main products were FA, tetrahydrofurfuryl alcohol (THFA), furan (F), methyltetrahydrofuran (MTHF), and methylfuran (MF). Table 1 summarizes the obtained results from the reaction of furfural over $\mathrm{Pt} / \mathrm{BC} 3 \mathrm{wt} \%$ catalyst in correlation to the operation parameters.

Hydrogenation rates have been previously reported to increase proportionally with temperatures [24] however, no clear tendency of this nature was observed for the actual experiments. For the experiments involving the catalyst with a $3 \mathrm{wt} \%$ platinum loading, the optimal temperature was reached at $210{ }^{\circ} \mathrm{C}$, showing a maximum conversion of $60.8 \%$ with $79.2 \%$ selectivity to FA after $2 \mathrm{~h}$ (Entry 9, Table 1). The yield of FA drops from $48.2 \%$ to $16.1 \%$ (Entry 8 ) when temperature decreases from $210{ }^{\circ} \mathrm{C}$ to $170{ }^{\circ} \mathrm{C}$. Even if a higher conversion value is observed at $320^{\circ} \mathrm{C}$ (Entry 13), the selectivity toward FA is $16.8 \%$ and the then FA yield decreases from $48.2 \%$ to $11.8 \%$. Moreover, results from Entries 10 and 11 also showed that increasing the reaction time only leaded to a slight modification 
of the conversion rate and an increased portion of furan, resulting in a decrease in selectivity to FA. This behavior was observed as well after addition of a higher amount of catalyst (Entry 5, Table 1).

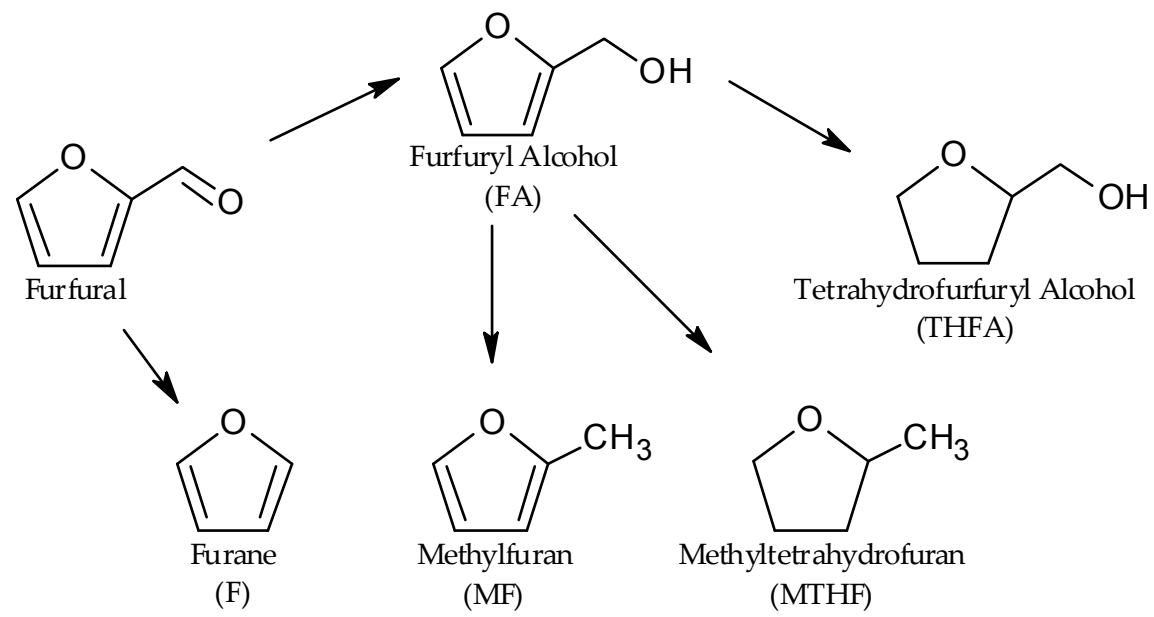

Figure 2. Possible reaction pathways for furfural hydrogenation.

Table 1. Experimental conditions, conversion, and selectivity for liquid phase furfural hydrogenation in toluene using the Pt/BC 3 wt \% catalyst. FA: furfuryl alcohol; TOF: turn-over frequency; THFA: tetrahydrofurfuryl alcohol; MF: methylfuran; and F: furan.

\begin{tabular}{|c|c|c|c|c|c|c|c|c|c|c|c|}
\hline \multirow{2}{*}{ Entry } & \multirow{2}{*}{$\begin{array}{l}\text { Catalyst } \\
\text { (mmol) }\end{array}$} & \multirow{2}{*}{$P($ psi) } & \multirow{2}{*}{$T\left({ }^{\circ} \mathrm{C}\right)$} & \multirow{2}{*}{$t(\mathrm{~h})$} & \multirow{2}{*}{$\begin{array}{c}\text { Conversion } \\
(\%)\end{array}$} & \multirow{2}{*}{$\begin{array}{c}\text { FA Yield } \\
(\%)\end{array}$} & \multirow{2}{*}{$\begin{array}{l}\text { TOF } \\
\left(\mathrm{s}^{-1}\right)\end{array}$} & \multicolumn{4}{|c|}{ Selectivity (\%) } \\
\hline & & & & & & & & FA & THFA & MF & F \\
\hline 1 & 0.025 & 500 & 210 & 2 & 20.1 & 6.9 & $4.0 \times 10^{-2}$ & 34.2 & - & 6.4 & 40.1 \\
\hline 2 & 0.025 & 500 & 250 & 2 & 18.4 & 3.9 & $3.7 \times 10^{-2}$ & 21.2 & - & 12.6 & 63.4 \\
\hline 3 & 0.025 & 1000 & 210 & 2 & 35.6 & 25.7 & $7.1 \times 10^{-2}$ & 72.2 & - & 6.6 & 20.1 \\
\hline 4 & 0.025 & 1000 & 250 & 2 & 36.4 & 17.0 & $7.3 \times 10^{-2}$ & 46.7 & 0.4 & 14.7 & 33.8 \\
\hline 5 & 0.058 & 1000 & 250 & 2 & 52.0 & 13.8 & $4.5 \times 10^{-2}$ & 26.6 & 0.1 & 13.0 & 58.8 \\
\hline 6 & 0.058 & 1000 & 250 & 1 & 30.1 & 11.4 & $5.2 \times 10^{-2}$ & 38.0 & - & 14.5 & 46.2 \\
\hline 7 & 0.025 & 1000 & 250 & 3 & 40.8 & 20.2 & $5.4 \times 10^{-2}$ & 49.6 & 0.2 & 19.1 & 29.8 \\
\hline 8 & 0.025 & 1500 & 170 & 2 & 19.4 & 16.1 & $3.9 \times 10^{-2}$ & 83.2 & 0.5 & 5.1 & 9.0 \\
\hline 9 & 0.025 & 1500 & 210 & 2 & 60.8 & 48.2 & $1.2 \times 10^{-2}$ & 79.2 & 0.4 & 8.5 & 11.0 \\
\hline 10 & 0.025 & 1500 & 210 & 4 & 66.9 & 55.4 & $6.7 \times 10^{-2}$ & 82.8 & 1.1 & 0.9 & 13.4 \\
\hline 11 & 0.025 & 1500 & 210 & 6 & 69.4 & 49.3 & $4.6 \times 10^{-2}$ & 71.1 & 0.7 & 12.8 & 14.7 \\
\hline 12 & 0.025 & 1500 & 250 & 2 & 33.4 & 27.1 & $6.7 \times 10^{-2}$ & 81.1 & 1.0 & 8.8 & 7.7 \\
\hline 13 & 0.025 & 1500 & 320 & 2 & 70.0 & 11.8 & $1.4 \times 10^{-2}$ & 16.8 & 0.6 & 35.2 & 43.2 \\
\hline 14 & 0.025 & 1500 & 300 & 3 & 59.9 & 10.1 & $8.0 \times 10^{-2}$ & 16.9 & 1.2 & 41.6 & 37.3 \\
\hline
\end{tabular}

Variation of the temperature in either direction from $210{ }^{\circ} \mathrm{C}$ impacts conversion and selectivity to FA (Entries 8, 9 and 12-14, Table 1) thus increasing the formation of byproducts as MF, furan, as well as other unknown compounds. One hypothesis explaining this phenomenon is probably related to catalyst selectivity that can be affected by adsorption of furfural and/or FA and by products on the surface of the catalyst's active sites.

Increasing $\mathrm{H}_{2}$ pressure from 500 psi to 1500 psi was shown to increase the conversion of furfural from $20.1 \%$ to $60.8 \%$ (Entries 1, 3 and 9, Table 1). The formation of byproducts at higher pressures of hydrogen does not appear to significantly affect the selectivity to FA, the latter increasing to $79.2 \%$ at 1500 psi conditions that were considered optimal for this catalyst and support. Results also showed that almost no THFA was formed for most of the tests performed with the Pt/BC catalyst, indicating that the latter was not intrinsically selective to $C-C$ double bonds thus prioritizing reduction of $C=O$ or $\mathrm{C}-\mathrm{OH}$ bonds. The tests using different amounts of catalyst ( $\mathrm{Pt} / \mathrm{BC} 1$ and $5 \mathrm{wt} \%$ ) were performed in the conditions that were shown optimal for a $3 \mathrm{wt} \%$ loading of catalyst (toluene as solvent, $210^{\circ} \mathrm{C}$, $1500 \mathrm{psi}$, for $2 \mathrm{~h}$ and $4 \mathrm{~h}$ ), as presented in Table 2. 
Table 2. Furfural hydrogenation results using $\mathrm{Pt} / \mathrm{BC} 3$ and $5 \mathrm{wt} \%$ as catalyst.

\begin{tabular}{cccccccccc}
\hline Entry & $\begin{array}{c}\text { Catalyst } \\
(\mathbf{m m o l )}\end{array}$ & $\boldsymbol{t}(\mathbf{h})$ & $\begin{array}{c}\text { Conversion } \\
(\mathbf{\%})\end{array}$ & $\begin{array}{c}\text { FA Yield } \\
(\mathbf{\%})\end{array}$ & TOF (s & & \multicolumn{3}{c}{ Selectivity (\%) } \\
\cline { 7 - 10 } & & 2 & 60.8 & 48.2 & $1.2 \times 10^{-2}$ & 79.2 & 0.4 & 8.5 & 11.0 \\
\hline 9 & \multirow{2}{*}{$0.025(3 \%)$} & 4 & 66.9 & 55.4 & $6.7 \times 10^{-2}$ & 82.8 & 1.1 & 0.9 & 13.4 \\
\hline 10 & & 2 & 40.5 & 31.3 & $4.6 \times 10^{-2}$ & 77.3 & 0.5 & 4.3 & 12.0 \\
\hline 15 & \multirow{2}{*}{$0.044(5 \%)$} & 4 & 45.3 & 32.4 & $2.5 \times 10^{-2}$ & 71.6 & 0.4 & 6.2 & 16.6 \\
\hline
\end{tabular}

Using a higher percentage of $\mathrm{Pt}$ in the catalyst but overall using the same amount of platinum based catalyst did not favor an increased conversion of furfural to FA compared with $3 \mathrm{wt} \%$ catalyst (Entries 9 and 10, Table 2). Furthermore, the use of higher quantity of impregnated metal (5 wt \%) was shown to reduce conversion of approximately $20 \%$ in both cases (Entries 15 and 16, Table 2). The reduced homogeneity of $\mathrm{Pt}$ distribution, being a consequence of the greater impregnation concentration, results in non-favorable conditions for furfural hydrogenation. Selectivity to FA was also shown to be significantly reduced and chromatograms showed the presence of new unknown byproducts, which did not occur at lower ( $3 \mathrm{wt} \%$ ) Pt content.

It should be noted that biochar per se was not inert in furfural hydrogenation, which was elucidated by testing only support at the same experimental conditions as above. Hydrogenation of furfural with the support alone results in conversion of $3.3 \%$ and selectivity to FA of $21.3 \%$, using the optimal conditions (identified by the tests on a $3 \mathrm{wt} \%$ loading of platinum). The biochar carbon surfaces and pores possess complex structures containing metals and oxygen groups, as well, the biochar has a tendency for fixation of metallic ion thus leading to a concentration of the plant inorganic content. As well, this functionality also allows the biochar to be a very efficient support for other types of metals, either for catalytic purposes or for soil remediation [27]. Overall, both the textural properties and the trace metal content in the biochar could be generating some activity. Furthermore, it is important to note that the support is stable under the reaction conditions and it does not interact with the solvent. Duplicate experiments were performed showing the rates and selectivity to the various products to be within an error margin of around $5 \%$, thus confirming reproducibility of the results.

The most important solvent effects in the hydrogenation of $\alpha, \beta$-unsaturated aldehydes are usually related to solvent polarity, solubility of hydrogen, and interactions between the catalyst and the solvent as well as solvation of reactants in the bulk liquid phase [28]. Further and as noted previously, both the support and the type of solvent can affect selectivity. As for this work, the solvent effect on the furfural hydrogenation was investigated with the $\mathrm{Pt} / \mathrm{BC} 3 \mathrm{wt} \%$ at $210{ }^{\circ} \mathrm{C}$ and $250{ }^{\circ} \mathrm{C}$ with a $\mathrm{H}_{2}$ pressure of 1500 psi for $2 \mathrm{~h}$ using toluene, isopropanol, isobutanol, and hexane. Results obtained for the hydrogenation of furfural using other solvents are shown in Table 3.

Table 3. Selectivity and conversion for furfural hydrogenation with $\mathrm{Pt} / \mathrm{B} 3 \mathrm{wt} \%$ in toluene, isopropanol, isobutanol, and hexane at $1500 \mathrm{psi}_{2}$ pressure for $2 \mathrm{~h}$.

\begin{tabular}{clcccccc}
\hline \multirow{2}{*}{ Entry } & \multirow{2}{*}{ Solvent } & $\mathbf{T}\left({ }^{\circ} \mathbf{C}\right)$ & $\begin{array}{c}\text { Conversion } \\
\mathbf{( \% )}\end{array}$ & $\begin{array}{c}\text { FA Yield } \\
\mathbf{( \% )}\end{array}$ & TOF (s $\left.{ }^{-1}\right)$ & \multicolumn{2}{c}{ Selectivity (\%) } \\
\hline 12 & \multirow{2}{*}{ Toluene } & 250 & 33.4 & 27.1 & $6.7 \times 10^{-2}$ & 81.1 & MF \\
\hline 9 & 210 & 60.8 & 48.1 & $1.2 \times 10^{-1}$ & 79.2 & 8.5 \\
\hline 17 & \multirow{2}{*}{ Isopropanol } & 250 & 37.5 & 21.1 & $7.5 \times 10^{-2}$ & 56.4 & 23.4 \\
18 & & 210 & 42.9 & 34.9 & $8.6 \times 10^{-2}$ & 81.3 & 9.0 \\
\hline 19 & \multirow{2}{*}{ Isobutanol } & 250 & 57.1 & 50.6 & $1.1 \times 10^{-1}$ & 88.6 & - \\
20 & & 210 & 82.8 & 49.6 & $1.7 \times 10^{-1}$ & 59.9 & - \\
\hline 21 & \multirow{2}{*}{ Hexane } & 250 & 66.4 & 16.1 & $1.3 \times 10^{-1}$ & 24.2 & - \\
22 & & 210 & 52.3 & 41.9 & $1.0 \times 10^{-1}$ & 80.2 & - \\
\hline
\end{tabular}


Utilization of isopropanol has led to the formation of dimerization products (Figure 3) that did not occur in toluene. The selectivity toward these products was close to $18 \%$ and $10 \%$ at $250{ }^{\circ} \mathrm{C}$ and $210{ }^{\circ} \mathrm{C}$, respectively. However, in both cases, the main product remained FA. Although conversion did increase, the difference was not significantly higher than what was noted for toluene at $250{ }^{\circ} \mathrm{C}$ (Entry 17 Table 3, and Entry 12 Table 3), and the selectivity to FA was shown to decrease, as a result of significant quantities of MF as well as dimerization products formed. At $210{ }^{\circ} \mathrm{C}$ (Entries 9 and 18 Table 3), conversion decreased to $23 \%$ in isopropanol although selectivity remained close to $80 \%$ in both cases. Isopropanol has a significant effect on the product's selectivity and formation of by-products is more pronounced. A hypothesis that could explain such observation would be that the greater availability of hydrogen in the media could lead to furfural and/or FA dimerization via a higher availability of radicals that could generate the end products depicted in Figure 3 below (identified by gas chromatograph coupled to mass spectrometer (GC-MS)).

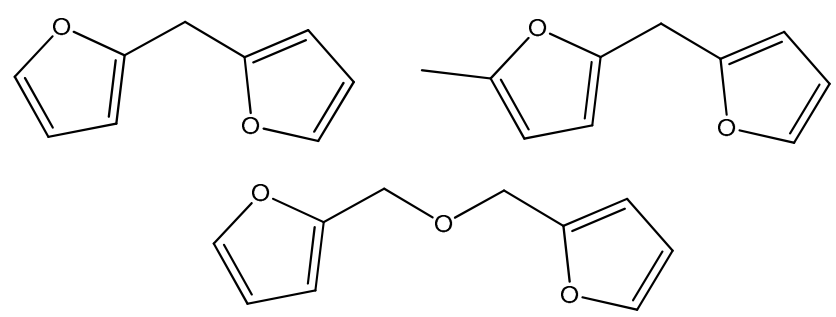

Figure 3. Observed dimers structures.

Utilization of bulky alcohols (as isobutanol) are supposed to lead to greater hydrogen solubility although it was not reported to correlate with an increased hydrogenation rate. The \% conversion in isobutanol seems to corroborate such assumptions. At $250{ }^{\circ} \mathrm{C}$, an increase in both conversion and selectivity toward alcohol was observed (Entry 19 Table 3). However, at $210{ }^{\circ} \mathrm{C}$, the selectivity was reduced by about $20 \%$.

Hexane (Entry 22, Table 3) gave results that were comparable to toluene at $210^{\circ} \mathrm{C}$ (Entry 9, Table 3) however, two liquid phases were obtained following the reaction and the possibility of finding products in both phases thus hinders quantification. The increased conversion noted at $250{ }^{\circ} \mathrm{C}$ (Entry 21, Table 3) over $210^{\circ} \mathrm{C}$ in hexane as compared to the other solvents is probably a result of the increased solubility of furfural in hexane as well as the formation of other unidentified condensation products.

All of the solvents that were used in this research lead to the production of MF and furan. However, dimerization and/or condensation products formation was affected by the solvent type and occurred essentially with a polar solvent.

\subsection{Catalyst Reactivation Test}

From Figure $4 \mathrm{a}$ it can be seen that the activity of reactivated $\mathrm{Pt} / \mathrm{BC}$ catalyst is retained in the first recycling (column 2) with regard to furfural hydrogenation in toluene at $210^{\circ} \mathrm{C}$ for $2 \mathrm{~h}$ (column 1), indicating no significant deactivation of the catalyst. On recycling a second time (catalyst undergoes three consecutive reactions with intermediary reactivation step, column 3, Figure 4a), there is a decrease in the conversion of furfural by almost $20 \%$. However, the selectivity to FA is not affected by the recycling of the catalyst (columns 1-3, Figure $4 b$ ).

At increased temperature $\left(320^{\circ} \mathrm{C}\right.$ ), conversion increased (column 4) compared to $210{ }^{\circ} \mathrm{C}$ (column 1), but the reactivation of the catalyst is not as effective as with the lower temperatures (there is a greater loss in the conversion of almost $12 \%$ ) and selectivity to FA is also seen to be reduced (less than $20 \%$ ). That indicates that temperature plays an important role in both catalyst activity and selectivity, further that deactivation of the catalyst occurs more readily at higher temperatures. Deactivation is assumed to be the result from a poisoning caused by strong chemisorption of compounds at the metal 
surface that cannot be solved during the reactivation step. The experiments shown in Figure 4 indicate that this catalyst has potential for recycling in furfural hydrogenation following process optimization.

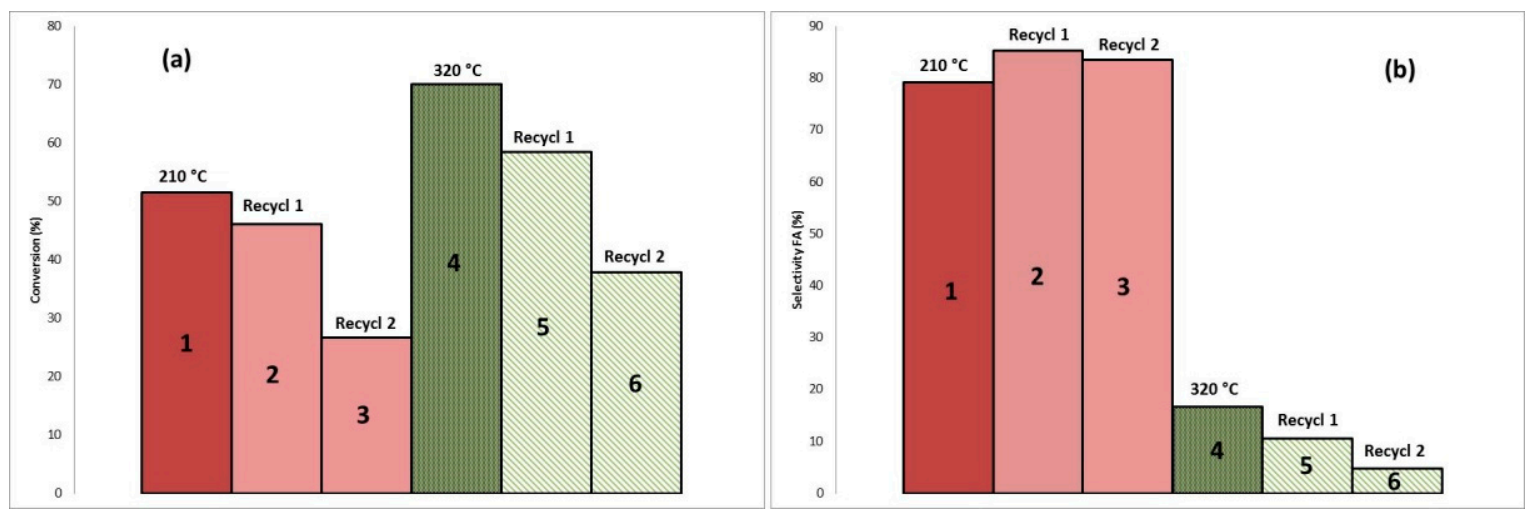

Figure 4. (a) Conversion; and (b) selectivity to FA at $210{ }^{\circ} \mathrm{C}$ (columns 1-3) and at $320^{\circ} \mathrm{C}$ (columns 4-6).

\section{Experimental}

\subsection{Support Preparation}

The biochar support was produced by torrefaction (slow pyrolysis) of sugar maple (Acer saccharum) sawdust in a continuous pilot scale Auger-type reactor under $\mathrm{CO}_{2}$ stream at atmospheric pressure. Biomass was obtained from Scierie Joseph Audet Inc. (Sainte-Rose-de-Watford, QC, Canada). Heating was performed countercurrent with a temperature gradient ranging inside the reactor from $230{ }^{\circ} \mathrm{C}$ to $400{ }^{\circ} \mathrm{C}$ with a residency time of about $5 \mathrm{~min}$. Prior to impregnation, biochar was treated twice by sonication in a $50 \%$ aqueous sulfuric acid solution. Finally, samples were washed with water and toluene, and then dried in an oven at $120^{\circ} \mathrm{C}$ overnight.

\subsection{Catalyst Preparation}

The platinum metal loading of the catalyst was achieved by wet impregnation using an aqueous solution of tetraammineplatinum (II) chloride hydrate (98\%, Sigma Aldrich, Saint Louis, MO, USA) in appropriate concentration so as to obtain $3 \mathrm{wt} \%$ and $5 \mathrm{wt} \% \mathrm{Pt}$ on the resulting catalyst. The impregnated sample was dried at $120{ }^{\circ} \mathrm{C}$ overnight to remove water. Prior to reaction, catalysts were activated in situ in flowing $\mathrm{H}_{2}(50 \mathrm{~mL} / \mathrm{min})$ at $250{ }^{\circ} \mathrm{C}$, for $1 \mathrm{~h}$.

\subsection{Catalyst Characterization}

The morphology and the elemental analysis of the catalyst were analyzed using a SEM model Hitachi S-4700 (Hitachi, Toyo, Japan) microscope equipped with an EDX (X-max $500 \mathrm{~mm}^{2}$, Oxford Instruments, Buckinghamshire, UK) system and operating with a voltage of $20 \mathrm{kV}$. The EDX used in this experiment was an Oxford model X-Max $50 \mathrm{~mm}^{2}$.

\subsection{Catalytic Test}

Liquid-phase hydrogenation of furfural was conducted in a $100 \mathrm{~mL}$ continuous stirred-tank reactor (CSTR) equipped with a reagent injection port, a gas inlet, and a vent (Figure 5). Hydrogenations were performed between $200{ }^{\circ} \mathrm{C}$ and $300{ }^{\circ} \mathrm{C}$ under a 500-1500 psi atmosphere of $\mathrm{H}_{2}$ (Praxair, purity 4.5), stirring at $600 \mathrm{rpm}$, for 1-6 h using toluene (99.99\%, bought from Anachemia, Lachine, QC, Canada), isobutanol (99\%, bought from Alfa Aesar, Ward Hill, MA, USA), $n$-hexane (95\%, bought from Anachemia, Lachine, QC, Canada), or 2-propanol (99.99\%, bought from Anachemia) as solvents. The reactor was loaded with $30 \mathrm{~mL}$ of solvent and $3 \mathrm{~mL}$ of furfural and the latter was reacted with different amounts of catalyst $(0.025-0.058 \mathrm{mmol}$ of Pt equivalent). The reactor was preheated to the 
desired temperature for the catalyst activation with a low flow of hydrogen, sample addition to the hot reactor and hydrogen pressurization was performed simultaneously.

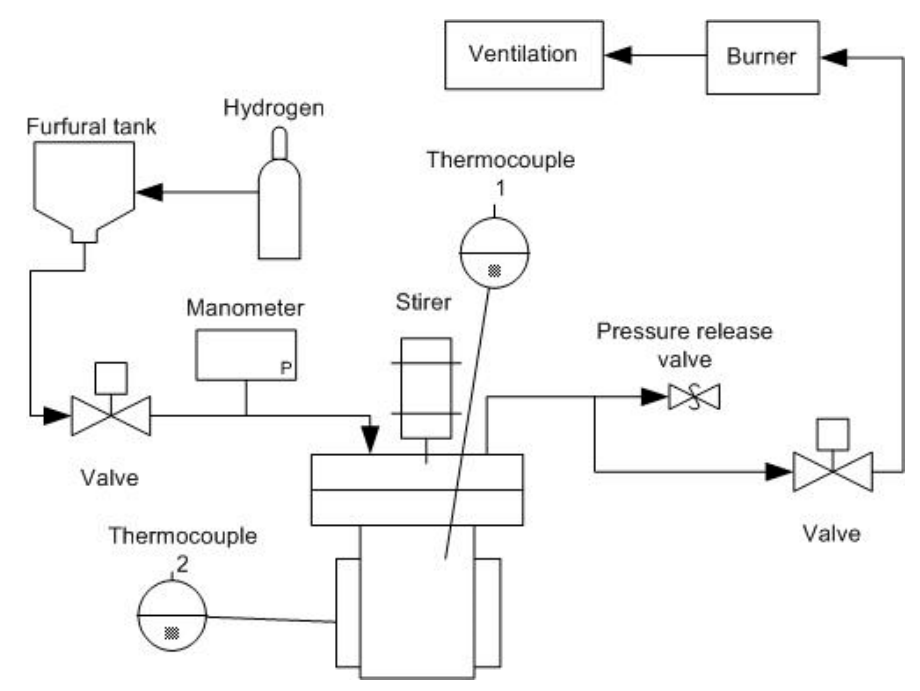

Figure 5. Process and instrumentation diagram for the liquid-phase hydrogenation of furfural.

The evolution of the reaction was followed using a GC-2014 gas chromatograph equipped (Shimadzu, Guelph, ON, Canada) with a flame ionization detector (FID), temperature programmer, and a capillary column Zebron ZB-5MS $(\mathrm{L}=30 \mathrm{~m} \times \mathrm{I}$.D. $=0.25 \mathrm{~mm} \times \mathrm{df}=0.25 \mu \mathrm{m})$ (Phenomenex, Torrance, CA, USA) with helium as carrier gas. The reaction products were FA, THFA, furan, MTHF, and MF.

Identification of the compounds present in the reaction mixture was performed using a Bruker Scion SQ GC-MS (Bruker Daltonics Inc., Milton, ON, Canada) equipped with Bruker CombiPAL autosampler, zebron capillary column (ZB-5MS, $60 \mathrm{~m}$ length, $0.25 \mathrm{~mm}$ I.D., $0.25 \mu \mathrm{m}$ film thickness), and a mass spectrum detector (Bruker SQ) using helium as carrier gas (Praxair, purity 5.0).

To compare the activity exhibited by the catalysts, the turn-over frequency (TOF) was calculated based on furfural conversion (Equation (1)):

$$
\mathrm{TOF}=\frac{\text { mmolfurfural converted }}{\text { time } * \text { mmol catalyst initial }}
$$

\subsection{Catalyst Regeneration Tests}

To investigate whether the catalyst could be reactivated, three consecutive experiments were performed at $210^{\circ} \mathrm{C}$ and $320^{\circ} \mathrm{C}$. Between the runs, the catalyst was washed repeatedly with toluene and dried. Reactivation of the catalyst was done each time as described in Section 3.2.

\section{Conclusions}

Results from this work show that biochar can be efficiently used as catalyst support in addition to being an economically and environmentally sound approach for furfural hydrogenation. The platinum-based catalyst produced from wet impregnation of a platinum salt on maple biochar proved to work well during liquid phase hydrogenation of furfural to FA and can be improved to favor the FA selectivity. Variation of temperature had an impact, both on conversion and selectivity to FA. Longer reaction times decrease selectivity to FA, with little or no effect on conversion showing that FA is an intermediate toward other reduction products as MF. Results also showed that solvent polarity tends to increase the hydrogenation rates but also the formation of dimerization and/or condensation products. Reaction conditions of $210{ }^{\circ} \mathrm{C}$ for $2 \mathrm{~h}$ and $1500 \mathrm{psi}$, with toluene as the solvent and $3 \mathrm{wt} \% \mathrm{Pt}$ 
content, were found to be optimal for $\mathrm{Pt} / \mathrm{BC}$ catalyst to favor furfural conversion at high selectivity to FA. Finally, the Pt/BC catalyst showed potential to be reactivated for further furfural hydrogenation reaction with a high selectivity to FA.

Acknowledgments: We would like to acknowledge the Industrial Chair in Cellulosic Ethanol and Biocommodities for financial support. The authors are also thankful to the Scierie Joseph Audet Inc. for providing the sugar maple samples. Finally, the authors are grateful to Charles Bertrand, research professional at the Materials Characterization Center, University of Sherbrooke, for his help with the SEM-EDX experiments.

Author Contributions: Ariadna Fuente-Hernández performed the catalyst loading, characterization and testing in reactor. She is also responsible for writing the part of the article that concerns these aspects. Roland Lee conceived and designed the experiments and wrote the first version of the article. Nicolas Béland co-designed, assembled and operated the pilot scale torrefaction unit. He produced the catalyst support and contributed to the corresponding part of the manuscript. Ingrid Zamboni contributed to the overall manuscript and catalyst interpretation. Jean-Michel Lavoie is the principal investigator of this work. He contributed to the overall concept, designed the experiments in collaboration with Ariadna Fuente-Hernández, and provided useful tips along the way, contributed to the design of the torrefaction unit. He reviewed the manuscript and composed both introduction and conclusion.

Conflicts of Interest: The authors declare no conflict of interest.

\section{References}

1. Lee, R.; Lavoie, J.M. From first- to third-generation biofuels: Challenges of producing a commodity from a biomass of increasing complexity. Anim. Front. 2013, 3, 6-11. [CrossRef]

2. Sánchez, O.J.; Montoya, S. Production of Bioethanol from Biomass: An Overview. In Biofuel Technologies; Springer: Berlin/Heidelberg, Germany, 2013; pp. 397-441.

3. Su, R.; Ma, Y.; Qi, W.; Zhang, M.; Wang, F.; Du, R.; Yang, J.; Zhang, M.; He, Z. Ethanol Production from High-Solid SSCF of Alkaline-Pretreated Corncob Using Recombinant Zymomonas mobilis CP4. BioEnergy Res. 2013, 6, 292-299. [CrossRef]

4. Tran, A.; Chambers, R.P. Red oak wood derived inhibitors in the ethanol fermentation of xylose by Pichia stipitis CBS 5776. Biotechnol. Lett. 1985, 7, 841-845. [CrossRef]

5. Fuente-Hernandez, A.; Corcos, P.O.; Beauchet, R.; Lavoie, J.M. Biofuels and co-products out of hemicelluloses. In Liquid, Gaseous and Solid Biofuels-Conversion Techniques; Fang, Z., Ed.; InTech: Rijeka, Croatia, 2013; p. 346.

6. Yang, W.; Li, P.; Bo, D.; Chang, H.; Wang, X.; Zhu, T. Optimization of furfural production from D-xylose with formic acid as catalyst in a reactive extraction system. Bioresour. Technol. 2013, 133, 361-369. [CrossRef] [PubMed]

7. Gürbüz, E.; Gallo, J.; Alonso, D.; Wettstein, S.; Lim, W.; Dumesic, J.A. Conversion of Hemicellulose into Furfural Using Solid Acid Catalysts in $\gamma$-Valerolactone. Angew. Chem. Int. Ed. 2013, 52, 1270-1274. [CrossRef] [PubMed]

8. Cai, C.M.; Zhang, T.; Kumar, R.; Wyman, C.E. Integrated furfural production as a renewable fuel and chemical platform from lignocellulosic biomass. J. Chem. Technol. Biotechnol. 2014, 89, 2-10. [CrossRef]

9. O'Driscoll, A.; Leahy, J.J.; Curtin, T. The influence of metal selection on catalyst activity for the liquid phase hydrogenation of furfural to furfuryl alcohol. Catal. Today 2015, 279, 194-201. [CrossRef]

10. Jiménez-Gómez, C.P.; Cecilia, J.A.; Durán-Martín, D.; Moreno-Tost, R.; Santamaría-González, J.; Mérida-Robles, J.; Mariscal, R.; Maireles-Torres, P. Gas-phase hydrogenation of furfural to furfuryl alcohol over $\mathrm{Cu} / \mathrm{ZnO}$ catalysts. J. Catal. 2016, 336, 107-115. [CrossRef]

11. Li, M.; Hao, Y.; Cárdenas-Lizana, F.; Keane, M.A. Selective production of furfuryl alcohol via gas phase hydrogenation of furfural over $\mathrm{Au} / \mathrm{Al}_{2} \mathrm{O}_{3}$. Catal. Commun. 2015, 69, 119-122. [CrossRef]

12. Wu, J.; Shen, Y.; Liu, C.; Wang, H.; Geng, C.; Zhang, Z. Vapor phase hydrogenation of furfural to furfuryl alcohol over environmentally friendly $\mathrm{Cu}-\mathrm{Ca} / \mathrm{SiO}_{2}$ catalyst. Catal. Commun. 2005, 6, 633-637. [CrossRef]

13. Vaidya, P.; MahajaniInd, V. Kinetics of Liquid-Phase Hydrogenation of Furfuraldehyde to Furfuryl Alcohol over a Pt/C Catalyst. Ind. Eng. Chem. Res. 2003, 42, 3881-3885. [CrossRef]

14. Sitthisa, S.; Pham, T.; Prasomsri, T.; Sooknoi, T.; Mallinson, R.; Resasco, D. Conversion of furfural and 2-methylpentanal on $\mathrm{Pd} / \mathrm{SiO}_{2}$ and $\mathrm{Pd}-\mathrm{Cu} / \mathrm{SiO}_{2}$ catalysts. J. Catal. 2011, 280, 17-27. [CrossRef]

15. Kijenski, J.; Winiarek, P. Selective hydrogenation of $\alpha, \beta$-unsaturated aldehydes over Pt catalysts deposited on monolayer supports. Appl. Catal. A Gen. 2000, 193, L1-L4. [CrossRef] 
16. Nagaraja, B.; Siva Kumar, V.; Shasikala, V.; Padmasri, A.; Sreedhar, B.; Raju, B.; Rama Rao, K. A highly efficient $\mathrm{Cu} / \mathrm{MgO}$ catalyst for vapour phase hydrogenation of furfural to furfuryl alcohol. Catal. Commun. 2003, 4, 287-293. [CrossRef]

17. Zhou, Z.; Ma, Q.; Zhang, A.; Wu, M. Synthesis of water-soluble monotosylated ethylenediamines and their application in ruthenium and iridium-catalyzed transfer hydrogenation of aldehydes. Appl. Organomet. Chem. 2011, 25, 856-861. [CrossRef]

18. Nakagawa, Y.; Tomishige, K. Production of 1,5-pentanediol from biomass via furfural and tetrahydrofurfuryl alcohol. Catal. Today 2012, 195, 136-143. [CrossRef]

19. Inada, K.; Shibagaki, M.; Nakanishi, Y.; Matsushita, H. The catalytic reduction of aldehydes and ketones with 2-propanol over silica-supported zirconium catalyst. ChemInform 1994, 25. [CrossRef]

20. Kijenski, J.; Winiarek, P.; Paryjczak, T.; Lewicki, A.; Mikołajska, A. Platinum deposited on monolayer supports in selective hydrogenation of furfural to furfuryl alcohol. Appl. Catal. A Gen. 2002, 233, 171-182. [CrossRef]

21. Nagaraja, B.; Padmasri, A.; David Raju, B.; Rama Rao, K. Vapor phase selective hydrogenation of furfural to furfuryl alcohol over Cu-MgO coprecipitated catalysts. J. Mol. Catal. A Chem. 2007, 265, 90-97. [CrossRef]

22. Li, H.; Luo, H.; Zhuang, L.; Dai, W.; Qiao, M. Liquid phase hydrogenation of furfural to furfuryl alcohol over the Fe-promoted Ni-B amorphous alloy catalysts. J. Mol. Catal. A Chem. 2003, 203, 267-275. [CrossRef]

23. Sitthisa, S.; An, W.; Resasco, D. Selective conversion of furfural to methylfuran over silica-supported Ni-Fe bimetallic catalysts. J. Catal. 2011, 284, 90-101. [CrossRef]

24. Baijuna, L.; Lianhaia, L.; Bingchuna, W.; Tianxia, C.; Iwatani, K. Liquid phase selective hydrogenation of furfural on Raney nickel modified by impregnation of salts of heteropolyacids. Appl. Catal. A Gen. 1998, 171, 117-122. [CrossRef]

25. Mäki-Arvela, P.; Hájek, P.; Salmi, J.; Murzin, T.; Yu, D. Chemoselective hydrogenation of carbonyl compounds over heterogeneous catalysts. Appl. Catal. A Gen. 2005, 292, 1-49. [CrossRef]

26. Dehkhoda, A.; West, A.; Ellis, N. Biochar based solid acid catalyst for biodiesel production. Appl. Catal. A Gen. 2010, 382, 197-204. [CrossRef]

27. Beesley, L.; Moreno-Jiménez, E.; Gomez-Eyles, J. Effects of biochar and greenwaste compost amendments on mobility, bioavailability and toxicity of inorganic and organic contaminants in a multi-element polluted soil. Environ. Pollut. 2010, 158, 2282-2287. [CrossRef] [PubMed]

28. Von Arx, M.; Mallat, T.; Baiker, A. Unprecedented selectivity behaviour in the hydrogenation of an $\alpha, \beta$-unsaturated ketone: Hydrogenation of ketoisophorone over alumina-supported Pt and Pd. J. Mol. Catal. A Chem. 1999, 148, 275-283. [CrossRef] 